\title{
How the personalities of medical students at the National University of Singapore differ from those of the local non-medical undergraduate population: a cross-sectional study
}

Lyn Li Lean ${ }^{1}$, MB BCh BAO, FCAI, Ryan Yee Shiun $\underline{H o n g}^{2}$, MSocSci, PhD, Lian Kah $\underline{T i}^{1}$, MBBS, MMed

\begin{abstract}
INTRODUCTION Integrity and willingness to contribute to society are desired traits of medical students beyond academic excellence. We investigated the personality traits of medical students at the National University of Singapore (NUS), who were about to become doctors. Personality traits were compared with a peer population of local university students.

METHODS This study was conducted between October 2013 and December 2014. Year 4 medical students were administered the Revised NEO (Neuroticism-Extraversion-Openness) Personality Inventory (NEO PI-R), a 240-item Likert scale personality test. Test data was analysed by an institutional psychologist and compared to a separate sample of 377 non-medical students who were peers at the same university taking psychology as a module. Data was collated and analysed.

RESULTS 65 Year 4 medical students completed the NEO PI-R personality test. The personalities of Year 4 medical students at NUS differed from their peers in all domains except for openness. NUS medical students generally had less neuroticism, and were more extroverted, agreeable and conscientious than their peers.

CONCLUSION Personality testing of NUS Year 4 medical students showed many of the desired traits of a doctor when compared to their peers at the same university.
\end{abstract}

Keywords: Asian, Big Five, college-aged, medical students, personality test

\section{INTRODUCTION}

Medicine at the Yong Loo Lin School of Medicine, National University of Singapore (NUS Medicine), is likely the most coveted tertiary education course in Singapore. Every year, more than 2,000 academically strong students, typically the cream of the graduating pre-university and polytechnic students, vie for 300-350 places in the programme.

In recent years, the admission selection process has been tweaked to not only select the brightest students but also students who possess desirable traits. These traits were outlined in a Straits Times article in 2010 by Singapore's then Minister of Education, Dr Ng Eng Hen, who said, "The interview panel assess attributes such as integrity, teamwork, willingness to contribute to society and communication skills-all of which are key traits of a good doctor."(1) To select the right students, aspiring students today participate in multiple interviews and roleplay situations during the application process to allow the assessors to tease out whether they possess the desired personality traits to become good doctors, beyond just being the brightest.

Work in psychology and behavioural science demonstrates that personality traits are influenced by genetic factors, likely become developed in childhood, and change with life or work experiences. ${ }^{(2-4)}$ Personality traits are relatively stable by the time students enter medical school, and undergraduate education serves as a refinery to mould our medical students into better doctors. The medical school, for its part, has created ample opportunities for students to learn compassion and communication skills by incorporating ethics, patient safety and community work into the curriculum, promoting a conducive environment for character moulding. ${ }^{(5)}$ However, media reports of unethical practice, ${ }^{(6)}$ such as outrageous overcharging, ${ }^{(7)}$ and negligence continue to dog the medical profession. ${ }^{\left({ }^{8}\right)}$

We therefore decided to test the personality of Year 4 medical students at NUS Medicine to observe if they possessed desirable personality traits at a time when they were a year away from becoming doctors.

\section{METHODS}

With institutional review board approval, the Revised NEO (Neuroticism-Extraversion-Openness) Personality Inventory ${ }^{(9)}$ (NEO PI-R) was administered to 65 consenting Year 4 medical students of a five-year undergraduate medical education course at NUS Medicine between October 2013 and December 2014. These students were recruited as part of a medical education study comparing different feedback techniques in the learning of a clinical procedure, which determined the sample size. Recruitment was by announcement before a class lecture by an investigator who was not involved in the students' teaching. Informed consent was obtained prior to the study.

The English version of the NEO PI-R Form S (self-reported) test for adults was used in this study. The test can be completed 
in approximately 30 minutes and consists of 240 Likert scale questions. This is an established and validated test of the five major personality traits, collectively known as the Big Five traits. The NEO PI-R has an internal consistency of $0.860-0.957$ and a retest reliability of $0.860-0.917 .{ }^{(9)}$

An institutional psychologist analysed the data and scored the personality domains and facets within each domain. To establish context, the personality data of the medical students was compared against that of a cohort of 377 non-medical students at NUS. As a previous study ${ }^{(10)}$ showed significantly higher personality trait scores for agreeableness, extroversion, openness and conscientiousness in medical students compared to those from the faculties of science, technology, engineering and mathematics, we anticipated similar findings in the population of NUS medical students when compared to a local non-medical cohort.

Data from NUS non-medical students was collected in 2008-2009 by the NUS Department of Psychology from students who attended a module in psychology. These students came from a variety of faculties: $60 \%$ were from the Faculty of Arts and Social Sciences; $25 \%$ were from the Faculty of Science; and the remaining 15\% were from the Faculty of Engineering, Faculty of Law and School of Business.

The results of the personality tests were relayed to all participating students via email after being scored by the institutional psychologist. Statistical analysis was performed using normalised $t$-test for age and each of the five personality traits, and chi-square test for gender between the groups using IBM SPSS Statistics version 22 (IBM Corp, Armonk, NY, USA). Analysis of covariance (ANCOVA) was utilised to statistically control for differences in age and gender between the groups.

\section{RESULTS}

Out of a total of 86 medical students posted to the National University Hospital's Anaesthesia Department, 70 medical students assigned to the department during the study period volunteered to take part in the research study. The Year 4 cohort comprised 467 students. Among these, 65 Year 4 medical students completed the NEO PI-R personality test. There were no significant differences in the ages of the non-medical students and medical students at NUS, which were 21.5 years and 22.1 years, respectively. There were, however, more women in the non-medical group $(60.4 \%)$ than in the medical group (46.2\%; $p=0.039)$.

The medical students differed from their non-medical peers on four of the five domains except for openness (Table I). The medical students were statistically more agreeable and had more conscientiousness than their non-medical peers. The medical students were also less neurotic and more extroverted than their non-medical peers.

When gender was accounted for using ANCOVA analysis (due to the higher proportion of females in the non-medical group), the significant results in Table I remained significant $(p<0.01)$, with the exception of openness $(p=0.922)$.
Table I. NEO PI-R domains of medical students vs. non-medical students at the National University of Singapore.

\begin{tabular}{|llll|}
\hline Domain & \multicolumn{2}{c}{ Mean \pm standard deviation } & p-value \\
\cline { 2 - 3 } & $\begin{array}{l}\text { Medical } \\
\text { students } \\
(\mathbf{n}=\mathbf{6 5})\end{array}$ & $\begin{array}{l}\text { Non-medical } \\
\text { students } \\
\text { (n=377) }\end{array}$ & \\
\hline Neuroticism & $85.9 \pm 23.4$ & $99.5 \pm 20.1$ & $<0.01^{*}$ \\
\hline Extroversion & $113.3 \pm 19.8$ & $105.7 \pm 19.9$ & $<0.01^{*}$ \\
\hline Openness & $112.7 \pm 17.4$ & $112.5 \pm 16.7$ & 0.45 \\
\hline Agreeableness & $127.4 \pm 17.5$ & $110.8 \pm 17.9$ & $<0.01^{*}$ \\
\hline Conscientiousness & $123.3 \pm 19.4$ & $107.6 \pm 19.7$ & $<0.01^{*}$ \\
\hline
\end{tabular}

${ }^{*} \mathrm{p}<0.05$ was considered statistically significant. NEO PI-R: Revised NEO (Neuroticism-Extraversion-Openness) Personality Inventory

\section{DISCUSSION}

The NEO PI-R is a measure of five personality characteristics or domains that differentiate one person from another and influence why we behave the way we do. These five domains are known as the Big Five personality traits and were originally derived in the 1970s by two independent research teams at the National Institutes of Health, United States, and a collaboration between the University of Michigan and the University of Oregon, United States. ${ }^{(9)}$ These teams determined that most human personality traits can be boiled down to five broad dimensions of personality regardless of language or culture: neuroticism, extroversion, openness, agreeableness and conscientiousness. The Big Five is the most widely accepted and used model for personality in scientific research, and is favoured by social scientists over lay personality tests, such as the Myers-Briggs Type Indicator, for its greater accuracy. ${ }^{(11)}$

NUS medical students were more conscientious and agreeable compared to their local non-medical peers. These traits are favourable for becoming a good doctor, as conscientiousness describes impulse control that facilitates thinking before acting, following norms and rules, and planning, organising and prioritising tasks. This helps doctors to avoid trouble and achieve high levels of success through purposeful planning and persistence. This is borne out in the medical literature, where adherence to best practices improves outcomes and enhances patient safety. ${ }^{(12)}$ In addition, thinking before acting on impulse is perceived as intelligence and reliability, key traits that reassure patients and next of kin that their doctor knows what he or she is doing. Furthermore, higher conscientiousness is predictive of success during the preclinical years of medical school ${ }^{(13)}$ and becomes more valuable as medical education progresses to the clinical years. ${ }^{(14)}$ Agreeableness is another important trait to possess, as it determines a medical student's ability to establish good rapport with patients and colleagues. ${ }^{(15,16)}$ In one crosssectional study of medical students, agreeable individuals were shown to be more empathetic than non-agreeable individuals. ${ }^{(17)}$

Medical students were also more extroverted compared to their non-medical peers. It is known that both extroverts and introverts make good doctors. However, considerable research has gone into matching personalities to the choice of medical specialty. The results showed, for example, that students selecting 
internal medicine had the highest agreeableness score than students from all other specialties. ${ }^{(18)}$

Interestingly, medical students were less neurotic compared to their non-medical peers. Neuroticism refers to the tendency to experience negative feelings, manifesting in anxiety, anger or depression. This is particularly important in specialties dealing with extremely sick patients, where the futility of treatment and death are more common. It has been shown that neuroticism has a strong negative association with the psychological health of medical students. ${ }^{(19)}$ Our results of lower neuroticism, in effect, could indicate that medical students are emotionally mature and resilient to psychological distress during medical school. They may be better able to deal with work burnout and job strain, have higher job satisfaction, ${ }^{(11)}$ and thus be less prone to commit unethical practices such as those detailed in the media.

For their medical school admission procedure, the medical students who participated in this study wrote a general essay and underwent two face-to-face interviews. While university admission to most courses other than medicine is based primarily on students' academic grades, medical school admissions, both locally and internationally, are progressively departing from selection based purely on cognitive abilities. Using personality testing in medical school admission may allow us to select more suitable candidates, from a social point of view, who are less neurotic, and more conscientious and agreeable.

The NEO PI-R is only one of many tests and has not been specifically used for medical student selection. Other tests, such as the Personal Qualities Assessment (PQA), have been shown to be useful in the medical school selection process, as they report on the empathy and motivation of students, which may be related to success during medical school. ${ }^{(20)}$ The PQA can be employed in an Asian setting, as recently demonstrated by its use in Japan. ${ }^{(21)}$ However, the PQA is designed for healthcare professionals and so may not be suitably extrapolated to nonmedical students. ${ }^{(22)}$ An example of other tests that can be considered are the Situational Judgement Tests, which were added to the admission procedure in a European medical school to not only find candidates who were good at the natural sciences, but also to assess their aptitude for handling theoretical social constructs in complex situations. ${ }^{(23)}$ However, the use of personality tests has also been questioned due to the lack of strong long-term outcome data and the fear that personality tests are susceptible to faking or coaching. ${ }^{(24)}$

It is tempting to postulate that our medical school selection process resulted in students with these appropriate personality traits being chosen, who are then moulded by a curriculum that emphasises development of communication skills and ethical conduct. A potential limitation of this line of deliberation is that possession of these desirable personality qualities inherently results in more impressive academic and extracurricular records, thus suggesting that a self-selection process could be at work. Also, as baseline personality testing was not available for participating students at the start of their university education, we were only able to examine a cross-sectional view of their personalities. Despite these drawbacks, our study suggested that the selection process for NUS medical students had adequately withstood four years of medical school, with good personality traits retained at Year 4.

Another possible limitation of this study was that the surveyed populations might not be representative, as has been highlighted by Grimes and Schulz. ${ }^{(25)}$ While the 65 medical students in our study represented only $14 \%$ of the Year 4 cohort, it constituted $75.6 \%$ of the total of 86 students who were assigned to the hospital's Anaesthesia Department during the study period. We therefore believe that any selection bias to have been small and the study population to be representative of their cohort. Similarly, for the non-medical students, it is unclear if students who chose to do a psychology module had different personalities from other students in their respective faculties. However, as these students came from five large faculties that represented $69 \%$ of the entire undergraduate student population at the university in $2015^{(26)}$ we believe that they were representative of all non-medical students as well.

Correctly selected medical students may still show poor attitudes or communication after graduation. Therefore, while there may be advantages to including personality testing as part of the medical school selection process, it may also be worthwhile to examine any changes in personality traits as medical students progress to internship and specialty training.

In conclusion, observations of the personalities of medical students who were on the cusp of graduating to become doctors showed them to be more conscientious, agreeable and extroverted, and less neurotic than their non-medical peers at the university. They suggest that the selection process and curriculum at NUS Medicine would produce the right type of doctors. Finally, it would be interesting to observe the personality traits of students once again after they embark on their medical careers, to find out if their traits change in the course of clinical work.

\section{REFERENCES}

1. Over $70 \%$ of local medical students were top A level grads. AsiaOne 2010 May 19. Available at: http://news.asiaone.com/News/Education/Story/ A1Story20100519-217124.html. Accessed October 20, 2016.

2. Hart D, Keller M, Edelstein W, Hofmann V. Childhood personality influences on social-cognitive development: a longitudinal study. J Pers Soc Psychol 1998; 74:1278-89.

3. Roberts BW, Mroczek D. Personality trait change in adulthood. Curr Dir Psychol Sci 2008; 17:31-5.

4. Roberts BW, Caspi A, Moffitt TE. Work experiences and personality development in young adulthood. J Pers Soc Psychol 2003; 84:582-93.

5. Yong Loo Lin School of Medicine, National University of Singapore. Medicine -Undergraduate. Available at: http://nusmedicine.nus.edu.sg/admissions/ medicine/undergraduate. Accessed October 12, 2016.

6. Khalik S. Complaints against doctors at all-time high. The Straits Times 2015 Nov 14. Available at: http://www.straitstimes.com/singapore/health/ complaints-against-doctors-at-all-time-high. Accessed January 3, 2018.

7. Average of 160 overcharging complaints made annually in last two years: $\mathbf{M O H}$. Channel NewsAsia 2017 Feb 28. Available at: http://www.channelnewsasia. com/news/singapore/average-of-160-overcharging-complaints-made-annuallyin-last-two-7617200. Accessed January 3, 2018.

8. Neo CC. More complaints against doctors, last year. TODAY 2017 Jun 29. Available at: http://www.todayonline.com/singapore/more-complaints-againstdoctors-last-year. Accessed January 3, 2018.

9. Costa PT Jr, McCrae RR. NEO PI-R professional manual. Odessa, FL: Psychological Assessment Resources Inc, 1992

10. Kötter T, Tautphäus Y, Scherer M, Voltmer E. Health-promoting factors in medical students and students of science, technology, engineering, and mathematics: design and baseline results of a comparative longitudinal study. BMC Med Educ 2014; 14:134 
11. John OP, Naumann LP, Soto CJ. Paradigm shift to the integrative big five trait taxonomy: history, measurement and conceptual issues. In: John OP, Robins RW, Pervin LA, eds. Handbook of Personality: Theory and Research. 3rd ed. New York, NY: Guilford Press, 2008: 114-58.

12. De Vries EN, Prins HA, Crolla RM, et al; SURPASS Collaborative Group. Effect of a comprehensive surgical safety system on patient outcomes. N Engl J Med 2010; 363:1928-37.

13. Ferguson E, James D, O'Hehir F, Sanders A, McManus IC. Pilot study of the roles of personality, references, and personal statements in relation to performance over the five years of a medical degree. BMJ 2003; 326:429-32.

14. Lievens F, Ones DS, Dilchert S. Personality scale validities increase throughout medical school. J Appl Psychol 2009; 94:1514-35.

15. Gough HG, Bradley P, McDonald JS. Performance of residents in anesthesiology as related to measures of personality and interests. Psychol Rep 1991; 68(3 Pt 1):979-94.

16. Shen H, Comrey AL. Predicting medical students' academic performances by their cognitive abilities and personality characteristics. Acad Med 1997; 72:781-6.

17. Costa P, Alves R, Neto I, et al. Associations between medical student empathy and personality: a multi-institutional study. PLoS One 2014; 17:e89254.

18. Maron BA, Fein S, Maron BJ, et al. Ability of prospective assessment of personality profiles to predict the practice specialty of medical students. Proc (Bayl Univ Med Cent) 2007; 20:22-6.
19. Yusoff MS, Esa AR, Mat Pa MN, et al. A longitudinal study of relationships between previous academic achievement, emotional intelligence and personality traits with psychological health of medical students during stressful periods. Educ Health (Abingdon) 2013; 26:39-47.

20. Lumsden MA, Bore M, Millar K, Jack R, Powis D. Assessment of personal qualities in relation to admission to medical school. Med Educ 2005; 39:258-65.

21. Fukui Y, Noda S, Okada M, et al. Trial use of the Personal Qualities Assessment (PQA) in the entrance examination of a Japanese medical university: similarities to the results in western countries. Teach Learn Med 2014; 26:357-63.

22. Powis D, Bore M, Munro D, Lumsden MA. Development of the personal qualities assessment as a tool for selecting medical students. J Adult Contin Educ 2005; 11:3-14.

23. Luschin-Ebengreuth M, Dimai HP, Ithaler D, Neges HM, Reibnegger G. Situational judgment test as an additional tool in a medical admission test: an observational investigation. BMC Res Notes 2015; 8:81.

24. Patterson F, Knight A, Dowell J, et al. How effective are selection methods in medical education? A systematic review. Med Educ 2016; 50:36-60.

25. Grimes DA, Schulz KF. Compared to what? Finding controls for case-control studies. Lancet 2005; 365:1429-33.

26. National University of Singapore. Summary of undergraduate student enrolment. Available at: http://www.nus.edu.sg/registrar/info/statistics/ug-enrol-20152016. pdf. Accessed October 20, 2016 